\title{
Integration of Remote Sensing Data with Electronic Government Information Resources at the Municipal Level
}

\author{
Tesalovsky A.A.* \\ Department of urban cadastre and geodesy \\ Vologda State University \\ Vologda, Russia \\ andrew-tesalovsky@yandex.ru \\ Avdeev Yu.M. \\ Department of urban cadastre and geodesy \\ Vologda State University \\ Vologda, Russia \\ avdeevyur@yandex.ru
}

\author{
Zavarin D.A. \\ Department of urban cadastre and geodesy \\ Vologda State University \\ Vologda, Russia \\ zavarin.denis@mail.ru
}

Titov D.V.

Department of Informatics and Mathematics

Vologda Institute of Law and Economics of the Federal

Penitentiary Service of Russia

Vologda, Russia

titov_dv@mail.ru

\author{
Anisimov N.V \\ Department of urban cadastre and geodesy \\ Vologda State University \\ Vologda, Russia \\ nvanisimov1@gmail.com
}

\begin{abstract}
The subject of the study is the need and the possibility of using remote sensing data in the absence of reliable information from electronic federal information resources and the geospatial binding of their data with a view to further data integration. The article discusses the main disadvantages and advantages of the use of unmanned aerial vehicles for electronic mapping on the example of lands outside the settlements. For all the advantages of using unmanned aerial vehicles for cartographic support of electronic state information resources, their use is difficult due to the insufficient development of the regulatory framework for their use for aerial photography of the area. With remote sensing, despite the ever-increasing accuracy of the data obtained, it is not yet possible to exclude groundbased measurements. It has been established that, on average, the share of agricultural land registered in the state cadastral registration, the location information of which is contained in the Unified State Register of Property Rights, decreases with distance from the borders of settlements. The use of modern technologies and methods of remote sensing allows solving a range of problems from legal and environmental ones to data exchange and integration with federal, regional and municipal information resources.
\end{abstract}

Keywords - unmanned aerial vehicles, remote sensing of the Earth, Unified State Register of Property Rights, agricultural land, cadastral registration, digital mapping

\section{INTRODUCTION}

Currently, measures are being taken to digitalize the economy, including the transition to maintaining state information resources in electronic form with geospatial reference of various databases. A vivid example of such an information resource, maintained in electronic form, constantly adjusted and updated, can serve as the Unified State Register of Property Rights (USRR). The USRR has been maintained by the Federal Service for State Registration, Cadastre and Cartography since 2017 after the merger of the State Real Estate Cadastre and the Unified State Register of Rights to Real Estate and Transactions. Data on real estate objects are geospatially referenced: the turning points of the contours are defined in a special coordinate system created for maintaining the USRR and can be combined with planning and cartographic material and Earth remote sensing data.

At the same time, the USRR is filled as cadastral work is completed and relevant information about real estate objects is entered: capital construction objects and land plots. Therefore, not every real estate object is adequately accounted for in the state information resource. Especially large number of land plots are unaccounted for in accordance with the established procedure outside the settlements.

However, the active circulation of plots and their use is also characteristic of lands outside the borders of settlements. And, since their location data about all of them can be 
obtained from state information resources, the problem arises of quickly obtaining information about the unique characteristics of such lands during economic activities within their borders. Often for large agricultural land plots there is only data on their area with an indication of the location in the form of a municipal district or rural settlement. In addition, the USRR contains information about land plots as objects of legal relations; other important characteristics are ignored.

The article considers the need and the possibility of using remote sensing data in the absence of reliable USRR information in the production and monitoring of agricultural lands. One of the main tasks is to determine how much the share of agricultural lands put on cadastral records decreases, information about which is entered into the USRR and the location of which can be unambiguously determined, when moving away from the borders of settlements.

\section{LITERATURE REVIEW AND METHODOLOGY}

Recently, in the works of Russian and international scientists, quite a lot of attention has been paid to the use of unmanned aerial vehicles (UAVs) and remote sensing of the Earth while monitoring the condition of vegetated territories and agricultural lands, and mapping the changes occurring within their boundaries.

For example, in Canada [4], for 15 years, plantations in national parks were monitored by remote sensing methods, the impact of anthropogenic and natural impacts on forests was assessed, changes were mapped, and the data formed the basis of the state report on the state of national parks. In Nigeria [8], when mapping forest areas in protected areas, data from remote sensing of land turned out to be irreplaceable when identifying and mapping by means of geographic information systems forest degradation sites associated with human activities and agriculture. Remote sensing data are actively used in monitoring specially protected natural areas in the Moscow region: based on surveys with a difference of 21 years, a change in the ratio of the areas of forests, meadows and other objects of a large reserve was established [13].

In scientific papers, the following general advantages of the use of UAVs for obtaining aerial photographs and remote sensing of the earth's surface are distinguished:

- different size range of UAVs that allows them flying at different heights for capturing images at various scales and obtaining digital images with different spatial resolutions [9];

- when monitoring remote and inaccessible territories, the life of the crew is not endangered [9];

- obtaining up-to-date digital information for planning environmental management [9], the ability to monitor the dynamics of land and landscape degradation by comparing the images with the data of previous surveys [5];

- low cost of monitoring the state of land and vegetation compared to ground-based methods, and compared to monitoring using helicopters equipped with similar imaging systems, is almost 6 times lower [2];
- remote sensing of lands from low altitudes with the use of UAVs makes it possible to obtain clouds of ultrahigh-density points, which contributes to the collection of information on the state of vegetation immediately over a large area with relatively low cost [7];

- the low cost of UAV application and image processing in specialized programs for monitoring land and the state of plantings within certain allotment limits for economic use [11];

- lack of requirements for highly qualified operator for servicing light UAVs [12];

- when shooting in the same territory at different times of the year, even only in the visible range, you can determine the species composition of plantings and track the dynamics [11];

- the accuracy of geospatial modeling using certain UAV models and programs for processing survey data meets the requirements for modeling objects in state information resources, for example, USRR [14].

At the same time, the disadvantages of using UAVs for land monitoring are also indicated:

- UAVs are more susceptible to weather conditions, their software and sensors have certain limitations [9];

- preferably simultaneous acquisition of remote sensing data of lands by UAV in various parts of the spectrum for the best determination of the state of the study area [6];

- despite the high mobility and speed of collection of digital information in terms of geometric accuracy, it is rarely possible to achieve maximum accuracy indicators of ground-based measurement methods [3];

- it is necessary to use algorithms to search for shaded areas in aerial photographs, ignoring which appreciably reduces the accuracy of calculating some indices important for monitoring land and vegetation status, for example, NDVI (normalized vegetation index) [1];

- it is important to constantly conduct comparative studies to identify appropriate UAVs and methods for processing remote sensing data for monitoring in certain conditions and in a particular area $[4,9]$;

- urgent need to standardize implemented equipment, software systems and the methods of survey and monitoring of land and vegetation using UAVs [10];

- insufficient elaboration of the regulatory framework for the use of UAVs for aerial photography of the area $[14,15]$, as one of the main obstacles to the widespread use of UAVs [15];

- to determine the boundaries of land use with the necessary accuracy, we still need to install sights on the ground [12]; 
- the process of solving the problems of monitoring ecosystems is still quite time-consuming even with the use of remote sensing data and geographic information systems, since the reliability of the results is affected by the quality of images, software and the expertise of the performer [13].

To solve the main task in the Vologda Oblast, a rural settlement quite remote from the regional center (the city of Vologda) was chosen - the Andreevsky rural settlement in the Vashkinsky municipal district. On the territory of the Andreevsky rural settlement, the largest settlements were selected: the village of Pervomaisky, the villages of Andreevskaya, Davydovo, Kononovo, Turzino, Ostrov and Bolshaya Chagotma. Near these settlements, agricultural activities are carried out. The geographical coordinates of the points are given in Table 1.

Around these settlements, three zones were conditionally defined:

- the first - within a radius of $0.5 \mathrm{~km}$ from the border of the village;

- the second - within a radius of $1.5 \mathrm{~km}$ from the border of the village;

- the third - within a radius of $2.5 \mathrm{~km}$ from the border of the village.

TABLE I. GEORAPHIC COORDINATES OF SETTLEMENTS

\begin{tabular}{|l|c|c|}
\hline \multirow{2}{*}{ Name of settlement } & \multicolumn{2}{|c|}{ Geographic coordinates } \\
\cline { 2 - 3 } & Latitude & Longitude \\
\hline Pervomaisky & $60.456554^{\circ}$ & $37.961180^{\circ}$ \\
\hline Andreevskaya & $60.482859^{\circ}$ & $37.920713^{\circ}$ \\
\hline Davydovo & $60.462443^{\circ}$ & $37.946886^{\circ}$ \\
\hline Kononovo & $60.458540^{\circ}$ & $37.945465^{\circ}$ \\
\hline Turzino & $60.484935^{\circ}$ & $37.906085^{\circ}$ \\
\hline Ostrov & $60.554673^{\circ}$ & $37.883723^{\circ}$ \\
\hline Bolshaya Chagotma & $60.564711^{\circ}$ & $37.862153^{\circ}$ \\
\hline
\end{tabular}

In each zone, the following were determined: the total area of agricultural land and the area of land put on cadastral registration, that is, those lands that are fully contained in the USRR and whose location can be unambiguously determined using the USRR. The areas were determined based on remote sensing data-satellite images from open sources, Yandex.Maps service. These images were scaled using AutoCAD tools; the farmland sections were outlined using the Polyline tool, and the areas were calculated analytically using the coordinates of the turning point vertices:

$$
P=\frac{1}{2} \sum_{\mathrm{i}=1}^{\mathrm{n}}\left(\mathrm{X}_{\mathrm{i}} \mathrm{Y}_{\mathrm{i}+1}-X_{i} Y_{i-1}\right)
$$

where $P$ is the plot area, sq. m.;

$\mathrm{X}$ is the $\mathrm{X}$-coordinate of the pivot point, $\mathrm{m}$;

$\mathrm{Y}$ is the $\mathrm{Y}$-coordinate of the pivot point, $\mathrm{m}$;

$i$ is the number of the pivot point, counting clockwise.
Then, using the service of the Internet portal of the Federal Service for State Registration, Cadastre and Cartography (Rosreestr), "Public Cadastral Map", it was determined which location information of which particular contours of agricultural land are cadastral and contained in the USRR.

\section{RESULTS}

When digitizing satellite images and designating zones around settlements of $0.5,1.5$ and $2.5 \mathrm{~km}$ wide, when vectorizing farmland contours, it was found that the villages are fairly close and, due to their proximity, common zones of the indicated radius, and the settlements themselves were formed in 3 groups:

- Andreevskaya and Turzino villages;

- villages of Davydovo, Kononovo and Pervomaisky;

- Ostrov and Bolshaya Chagotma villages.

Table 2 shows the data on the areas of agricultural land plots obtained by measuring data on remote sensing land using AutoCAD software by the zones around the lands of settlements, information about which is contained in the USRR and which are not yet included in the information resource.

TABLE II. AREAS OF AGRICULTURAL LAND PLOTS NEAR SETTLEMENTS

\begin{tabular}{|l|c|c|c|}
\hline \multirow{2}{*}{$\begin{array}{c}\text { Zones/ Presence } \\
\text { of land } \\
\text { information in } \\
\text { the USRR }\end{array}$} & $\begin{array}{c}\text { Andreevskaya, } \\
\text { Turnzino }\end{array}$ & $\begin{array}{c}\text { Lavydovo, } \\
\text { Kononovo, } \\
\text { Pervomaisky }\end{array}$ & $\begin{array}{c}\text { Ostrov, Big } \\
\text { Chagotma }\end{array}$ \\
\cline { 2 - 4 } $\begin{array}{l}\text { 0.5 km, } \\
\text { total land }\end{array}$ & 1058643 & 787370 & 1559722 \\
\hline $\begin{array}{l}0.5 \mathrm{~km}, \\
\text { data in USRR }\end{array}$ & 769370 & 108321 & 449200 \\
\hline $\begin{array}{l}1.5 \mathrm{~km}, \\
\text { total land }\end{array}$ & 2622437 & 1836665 & 908320 \\
\hline $\begin{array}{l}1.5 \mathrm{~km}, \\
\text { data in USRR }\end{array}$ & 1298400 & 245034 & 240000 \\
\hline $\begin{array}{l}2.5 \mathrm{~km}, \\
\text { total land }\end{array}$ & 1683754 & 2139928 & 929000 \\
\hline $\begin{array}{l}2.5 \mathrm{~km}, \\
\text { data in USRR }\end{array}$ & 325800 & 0 & 174000 \\
\hline
\end{tabular}

After that, according to the results of determining the areas of land plots in three zones around the lands of settlements of $0.5 \mathrm{~km}, 1.5 \mathrm{~km}$ and $2.5 \mathrm{~km}$, the share of agricultural land plots was determined, the information on which is fully contained in the USRR as the ratio of the areas of such plots in each zone to the total number of agricultural land plots in the same zone:

$$
P_{\%}=\frac{P_{\text {cadastre }}}{P_{\text {total }}} 100 \%,
$$

where $P_{\%}$ is the share of the plots, $\%$;

$P_{\text {cadastre }}$ is the area of agricultural land, the location of which is contained in the USRR, within a zone, sq. m;

$P_{\text {total }}$ total area of agricultural land within a zone, sq.m.

The data on certain shares are presented in Table 3. 
TABLE III. SHARE OF LAND PLOTS, INFORMATION ABOUT WHICH IN FULL VALUE IS CONTAINED IN USRR, IN ZONES WIDTH OF 0.5 KM, 1.5 KM AND 2.5 KM

\begin{tabular}{|l|c|c|c|}
\hline \multirow{2}{*}{$\begin{array}{c}\text { Name of } \\
\text { settlement }\end{array}$} & \multicolumn{3}{|c|}{$\begin{array}{c}\text { Share of agricultural land registered in } \\
\text { cadastral register [\%] }\end{array}$} \\
\cline { 2 - 4 } & within $\mathbf{0 . 5} \mathbf{~ k m}$ & within $\mathbf{1 . 5} \mathbf{~ k m}$ & within $\mathbf{2 . 5} \mathbf{~ k m}$ \\
\hline $\begin{array}{l}\text { Andreevskaya, } \\
\text { Turnzino }\end{array}$ & 72.7 & 49.5 & 19.4 \\
\hline $\begin{array}{l}\text { Davydovo, } \\
\text { Kononovo, } \\
\text { Pervomaisky }\end{array}$ & 13.7 & 13.3 & 0 \\
\hline $\begin{array}{l}\text { Ostrov, Big } \\
\text { Chagotma }\end{array}$ & 28.8 & 26.4 & 18.7 \\
\hline
\end{tabular}

On average, the share of agricultural land registered in the state cadastral register decreases with distance from settlements and on average in the zones around the largest settlements of the Andreevsky rural settlement of the Vashkinsky municipal district is:

- for lands remote at $0.5 \mathrm{~km}$ or less $-38.4 \%$;

- for lands remote at $0.5-1.5 \mathrm{~km}$ of lands $-29.4 \%$;

- for lands remote at $1.5-2.5 \mathrm{~km}, 12.7 \%$.

Thus, it has been established that sufficient information on the location of agricultural lands for their identification on the ground is not in the USRR for all such lands, and when they are removed from settlements, their number decreases even more. In the absence of the specified information in the state information resource, it is possible to obtain data on the location and other unique characteristics of the land using remote sensing data. An important aspect in this case remains the choice of the appropriate methodology for collecting and processing data, UAVs.

Of the existing complexes, one can cite an example- the product line of the company Geoscan. For the purposes of remote sensing of land, UAVs themselves, a ground control station, and a set of software modules have been developed that allow planning a flight, performing aerial photography, "stitching" the images received during the flight into a single image and obtaining the result necessary for a specific user: from a point cloud and a thematic photographic plan to a full three-dimensional terrain model.

Obtained during regular monitoring by remote sensing methods of the above lands in the area of settlements of Pervomaisky, Andreevskaya, Davydovo, Kononovo, Turzino, Ostrov and Bolshaya Chagotma, where agricultural production is carried out, can solve a whole range of problems.

First, to establish whether all land intended for it has been introduced into agricultural production. In general, for each household, the total area allocated to it is known. Part of the land can be separated and cadastrally registered with a fixed location, which will have a corresponding entry in the USRR. There are no problems with such land plots, because by their coordinates contained in the USRR, you can establish a location on the ground. For the rest of the land, only the total area is known. Thus, when aerial photography and combining its results with spatial data, you can establish the location of the rest allocated for the production of land.
Secondly, according to aerial photography, it is possible to determine whether large areas of land are cultivated than allocated. Information about the allocated areas without reference to the location is contained in the USRR. The establishment of this will allow not to "interfere" with unallocated land, avoiding violations of land legislation. The fine for legal entities for the unauthorized occupation of land is 100,000 rubles and above.

And thirdly, the prompt and continuous receipt of digital information when monitoring the condition and use of land by remote sensing methods allows tracking the dynamics of the state in retrospect. This will help to ensure the planning of rational and sustainable nature management, predict land degradation and take measures to protect them. When using digital data and processing it using geographic information systems, there is always the possibility of exchanging it with other information resources and integrating through exchange formats. When using modern UAVs, it is possible to obtain digital aerial photography data for an area of 7 to $22 \mathrm{~km}^{2}$ in one flight.

\section{CONCLUSION}

On the territory of Russia, a lot of federal information resources are being maintained, including geographically linked databases. An example of such an information resource is the USRR. Since the USRR is constantly "filled" with information about land plots, at the time of contacting it, not all the necessary data about the land plot may be available. Therefore, it becomes necessary to integrate the data of the federal information resource with the data of a specific land user.

When moving away from settlements, the proportion of land delivered in accordance with the current legislation decreases, in contrast to the amount of land itself. Land users, especially in the field of agricultural production, have a need to obtain relevant spatial data using remote sensing methods, which allows a whole complex of problems to be solved. It is established whether all land intended for it has been introduced into agricultural production. It is established whether there is a violation of land legislation during the unauthorized seizure of land from municipal, regional or state property. Continuous monitoring of the condition and use of land by remote sensing methods allows rational land use to be planned. When using digital data, it is possible to exchange them with other information resources and integrate through exchange formats.

With all the advantages of using UAVs for the cartographic support of electronic government information resources, one can note the insufficient development of the regulatory framework for the use of UAVs for aerial photography of the area, which is currently one of the main impediments to their widespread use. With remote sensing, despite the ever-increasing accuracy of the data obtained, it is not yet possible to exclude ground-based measurements.

\section{References}

[1] M. Aboutalebi, A.F. Torres-Rua, W.P. Kustas et al., "Assessment of different methods for shadow detection in high-resolution optical 
imagery and evaluation of shadow impact on calculation of NDVI, and evapotranspiration", Irrigat. Sci., vol. 37, pp. 407-429, 2018.

[2] B.R. Christensen, "Use of UAV or remotely piloted aircraft and forward-looking infrared in forest, rural and wildland fire management: evaluation using simple economic analysis", New Zealand J. of Forestry Sci., vol. 45 , no. 16 , pp. 1-9, 2015 .

[3] X. Liang, Y. Wang, X. Yu et al., "Forest in situ observations using unmanned aerial vehicle as an alternative of terrestrial measurements", Forest Ecosyst., vol. 6, no. 20, pp. 1-16, 2019.

[4] R.H. Fraser, I. Olthof, D. Pouliot, "Monitoring land cover change and ecological integrity in Canada's national parks", Remote Sens. of Environment, vol. 113, pp. 1397-1409, 2009.

[5] A.L. Mitchell, A. Rosenqvist, B. Mora, "Current remote sensing approaches to monitoring forest degradation in support of countries measurement, reporting and verifcation (MRV) systems for REDD+", Carbon Balance Manag., vol. 12, no. 9, pp. 1-22, 2017.

[6] L. Han, G. Yang, H. Dai et al., "Modeling maize above-ground biomass based on machine learning approaches using UAV remote-sensing data", Plant Methods, vol. 15, no. 10, 2019.

[7] J.R. Kellner, J. Armston, M. Birrer, "New Opportunities for Forest Remote Sensing Through Ultra-High-Density Drone Lidar", Surveys in Geophysics, no. 40, pp. 959-977, 2019.

[8] O.S. Olokeogun, O.F. Iyiola, K. Iyiola, "Application of remote sensing and GIS in land use/land cover mapping and change detection in Shasha
Forest Reserve, Nigeria", The Int. Archives of the Photogrammetry, Remote Sensing and Spatial Inform. Sci., vol. XL-8, pp. 613-616, 2014.

[9] L. Tang, G. Shao, "Drone remote sensing for forestry research and practices", J. of Forestry Res., vol. 4, pp. 791-797, 2015.

[10] J. Tigges, T. Lakes, "High resolution remote sensing for reducing uncertainties in urban forest carbon offset life cycle assessments", Carbon Balance and Management, vol. 12, no. 17, pp. 1-18, 2017.

[11] S.A. Denisov, A.A. Domrachev, A.S. Yelsukov, "Experience in using a quadrocopter to monitor forest restoration", Bull. of the Volga State Technol. Univer. Ser.: Forest, Ecol., Nature Manag., vol. 4, pp. 34-46, 2016.

[12] S.V. Koptev, O.V. Skudneva, "On the possibilities of using unmanned aerial vehicles in forestry practice", Izv. Vysshikh Uchebnykh Zavedenii, Forest J., vol. 1, pp. 130-138, 2018.

[13] I.A. Mirtova, E.A. Naumova, "The study of long-term changes in ecosystems of specially protected natural areas of the Moscow region according to remote sensing of the Earth", Izv. Vysshikh Uchebnykh Zavedenii, Surveying and Aerial Photogr., vol. 3, pp. 79-86, 2017.

[14] O.A. Aprilova, Development of requirements for the collection and processing of aerial photography data from unmanned aerial vehicles for modeling geospace: specialty 25.00.34" Aerospace exploration of the Earth, photogrammetry (Cand. dissertation thesis), 2018.

[15] M.I. Epov, I.N. Zlygostev, "Use of unmanned aerial vehicles in airborne geophysical reconnaissance", Iterexpo Geo-Siberia, vol. 3, pp. 22-27, 2012. 